\section{The effect of long N-ITR intervals upon the PRE*}

\author{
JOHN E. ARNOLD† and MITRI E. SHANAB \\ Fresno State College, Fresno, Calif. 93710
}

Six groups of male albino rats were given one trial a day for 19 days in a straight runway according to a 3 by 2 design. Schedule of reinforcement was varied in three ways: partial reinforcement with intertrial reinforcement (ITR) after nonrewarded $(N)$ trials, which preceded rewarded $(R)$ trials, partial reinforcement with ITR following selected $R$ trials, and consistent reinforcement with ITR given according to one or the other of the above ITR schedules. The administration of ITR occurred either 2 or $24 \mathrm{~h}$ after four designated trials. The results of 24 extinction trials did not support predictions based on the view that the aftereffects of nonreward remain readily replaceable over long periods of time.

An attenuated partial reinforcement effect (PRE) has reliably been found when relatively few intertrial reinforcements (ITRs) have been given in the goalbox of the regular training runway after nonrewarded $(\mathrm{N})$ trials which precede rewarded (R) trials (e.g., Capaldi \& Olivier, 1967). Capaldi (1967) has maintained that ITR given in the above manner interrupts the conditioning of the aftereffect of nonreward $\left(\mathrm{S}^{\mathrm{N}}\right)$ to the instrumental appraoch response $\left(R_{I}\right)$ by replacing $S N$ with the aftereffect of reward (SR) before $R_{I}$ is emitted and rewarded. Under such circumstances a partially reinforced $S$ and $a$ consistently reinforced $\mathbf{S}$ should perform similarly in extinction, as each $\mathrm{S}$ would have experienced rewarded instrumental responses solely in the presence of $\mathbf{S R}$.

Lobb \& Runcie (1967) objected to Capaldi's aftereffects hypothesis by noting that the 15-sec interval used in prior ITR studies between $\mathrm{N}$ trials and ITR might have interfered with the development of anticipatory frustration, $r_{F}-S_{F}$. With a longer $N$-ITR interval, sufficient time would be available for consolidation of $\mathrm{r}_{\mathrm{F}}-\mathrm{S} F$. To test this hypothesis, Lobb \& Runcie (1967) used two N-ITR intervals. While a 15-sec N-ITR group revealed an attenuated $P R E$ in extinction relative to a control group receiving ITR after $R$ trials, a 1-h N-ITR group did not, thereby supporting their hypothesis of the consolidation of conditioned frustration.

A subsequent aftereffects reinterpretation of Lobb \& Runcie's (1967) results was made by Capaldi \& Wilson (1968), based on the results of an earlier study by Capaldi \& Minkoff (1966). The latter found that resistance to extinction $(\mathrm{Rn})$ decreased

*Based on the first author's Master's thesis.

$\dagger$ Now at the University of California, Santa Barabara, Califormia, 93106. for partially reinforced $\mathrm{Ss}$, when the intertrial interval (ITI) used in extinction differed from that used in acquisition between $N$ and $R$ trials. Making the assumption that ITR acts in some respects similar to an $\mathrm{R}$ trial, Capaldi \& Wilson (1968) suggested that the 24-h extinction ITI of the Lobb \& Runcie (1967) study resembled more closely the $1-h$ acquisitional $\mathrm{N}$-ITR interval than the 15-sec one. As would be expected from such a hypothesis, the group which received the longer N-ITR interval exhibited greater Rn than the group which was trained under the shorter N-ITR interval. However, a finding left unexplained by the Capaldi \& Wilson (1968) reinterpretation of the above study is the equality in $\mathrm{Rn}$ of the two partially reinforced groups experiencing 1-h intervals between regular runway trials and ITR. This lack of difference between the two groups is surprising because, if one is to accept the assumption that ITR serves like an $R$ trial, the group that experienced a $1-h$ N-ITR interval in acquisition should have exhibited less $\mathrm{Rn}$ than the group which experienced a $24-\mathrm{h} \mathrm{N}-\mathrm{R}$ interval which was the same ITI interval used

An effort was made in the present study to avoid the possibility of confounding results arising from differences between the extinction ITI and the N-ITR interval used in acquisition. For all six groups the acquisition and extinction ITI was $24 \mathrm{~h}$. Furthermore, a 24-h N(R)-ITR interval was adhered to with respect to three of the six groups. The other three groups experienced a 2-h interval between the end of a regular runway trial and ITR.

The present study can be viewed as providing maximal conditions for the noninterference of ITR with the development of anticipatory frustration. At the same time, the adoption of long N-ITR intervals in extinction. enables a test to be made of the sequential assumption that aftereffects of nonreward remain functional until replaced by other aftereffects.

\section{METHOD}

The Ss were 42 naive male Sprague-Dawley rats, approximately 70 days old at the beginning of the experiment. A 67.5-in. unpainted redwood runway was used. Two wooden guillotine doors divided the runway into a $7 \times 6.5 \mathrm{in}$. startbox, a $48.5 \times 4$ in. alleyway, and a $12 \times 5$ in. goalbox. The floors of the startbox and alley were constructed of redwood, while the floor of the goalbox was made of brass rods, spaced $.5 \mathrm{in}$. apart. All sections were 9 in. high and covered with clear Plexiglas. Photoelectric cells located $2.75,8.75,40.75$, and 52.75 in. from the startbox were connected to three .01-sec Standard Electric timers which measured start, run, and goal times, respectively.

Beginning on Day 4, all Ss were placed on a 12-g Purina lab chow diet and reduced to $80 \%$ of their free-feeding weights. During Days 4-27, each $S$ was individually handled for $1 \mathrm{~min}$ a day and allowed to eat three .045-g Noyes pellets from a 3-in.-diam glass dish, later placed in the goalbox during acquisition and extinction. Ss were separately given $2 \mathrm{~min}$ of free exploration in the unbaited runway with all photoelectric and timing mechanisms functioning on Days 28-29. During Days 30-40, 11 irregularly scheduled unbaited (no food dish) runway trials were given each $\mathbf{S}$, one trial a day. Upon entering the goalbox, $\mathbf{S}$ was immediately removed and returned to his home cage. Ss were then assigned randomly to one of six groups, comprising a 3 by 2 factorial design. Schedule of reinforcement was varied in three ways: partial reinforcement with ITR after $\mathbf{N}$ trials, which preceded $\mathbf{R}$ trials (PN), partial reinforcement with ITR following selected $R$ trials (PR), and consistent reinforcement with ITR given according to either the PN's or the PR's ITR schedule (C). ITR was administered either 2 or $24 \mathrm{~h}$ after the appropriate acquisition trials. Accordingly, the six groups were designated as follows: PN2, PN24, PR2, PR24, C2, and C24. On each of Days $41-43$, Ss received a baited (10-pellet) direct placement in the goalbox. On all placements and ITRs, $\mathrm{E}$ positioned S directly over the food dish. Regular acquisition trials began on Day 44, with each $S$ being given one trial a day in a fixed running order, randomly determined. The following schedule of partial reinforcement was used by Capaldi \& Spivey (1964, Experiment 2) and followed in this experiment: Trials 5, 
$7,8,11,12,15,16$, and $i 7$ were nomreinforced; ITR for PN and half of C Ss occurred after Trials 5, 8, 12, and 17. ITR for PR and the rest of C Ss was presented after Trials $6,9,14$, and 18. Ten .045-g Noyes pellets were given on $\mathrm{R}$ and ITR trials. On $\mathrm{N}$ trials $\mathrm{S}$ was detained for $15 \mathrm{sec}$ in the goalbox before being returned to his home cage. Ten minutes later $\mathrm{S}$ was fed his 12-g maintenance diet. Two hours after the appropriate trial, those Ss assigned to the 2-h N(R)-ITR condition were placed directly by $E$ into the baited goalbox, where they remained until all pellets were eaten. A similar procedure was followed for Ss assigned to the 24-h N(R)-ITR condition. Before daily trials were begun, a reinforced placement was given to each of the first half of the Ss due to received their 24-h ITR. Midway through the daily trials, approximately $5 \mathrm{~min}$ were spent in administering ITRs to the second half of the designated Ss. Thereafter, the normal fixed-order running pattern was resumed. All $S s$ received 24 extinction trials at a 24-h ITI. On each extinction trial an empty food dish was present in the goalbox and the $S$ was detained there for $15 \mathrm{sec}$.

RESULTS AND DISCUSSION

Acquisition analyses were based on total runway speeds (ft/sec). Separate two-way analyses of variance performed on the first four and last four acquisition trials yielded $F$ values of less than 1, indicating a lack of significant differences between groups either at the beginning or end of acquisition.

Since extinction data (total runway speeds) revealed little response decrement for partially reinforced groups, an extinction index (Shanab \& Cotton, 1970) was developed to depict each group's performance relative to its terminal acquisition level of responding. This was accomplished by dividing each S's mean total runway speed per block of three trials by the mean speed of his last five acquisition trials. Any resulting score greater (or smaller) than 1 would indicate that $S$ was responding faster (or slower) in extinction than in terminal acquisition. The graphed results are presented in Fig. 1 in blocks of three trials.

A repeated-measures two-way analysis of variance test of the extinction-index scores yielded a significant schedules main effect, $F(2,36)=11.045, \quad p<.001$, and $a$ significant Schedules by ITR interaction, $F(2,36)=3.974, \mathrm{p}<.05$. The latter indicated that while C24 was more resistant to extinction than $\mathrm{C} 2$, the same was not true for the partially reinforced groups. The block effect was also significant, $F(7,252)=17.019, \quad \mathrm{p}<.001 . \quad \mathrm{A}$ Schedules by Block interaction effect was found, $F(14,252)=2.898$, $\mathrm{p}<.001$, indicating a faster rate of response decrement for the consistently rewarded $S$ s relative to the partially rewarded Ss.

Post hoc $F$ tests of the schedules effect revealed that consistently rewarded $S$ s extinguished reliably faster than either PR Ss, $F(1,36)=16.996, p<.001$, or PN Ss, $F=16.130, p<.001 . P N$ and $P R$ Ss did not differ significantly from one another, $F<1$. On the other hand, Group C24 was significantly more resistant to extinction than Group C2, $F(1,36)=6.274, p<.025$. The latter, unexpected finding indicates that a PRE can be obtained between two consistently reinforced groups, depending on whether the Ss are intermittently reinforced (in the form of ITR) before or after the initiation of a standard consistently reinforced trial. A somewhat similar finding was reported by McCain \& Power (1966) when either an intermittent or consistent reinforcement schedule was introduced in the startbox for Ss that were otherwise consistently reinforced in the goalbox.

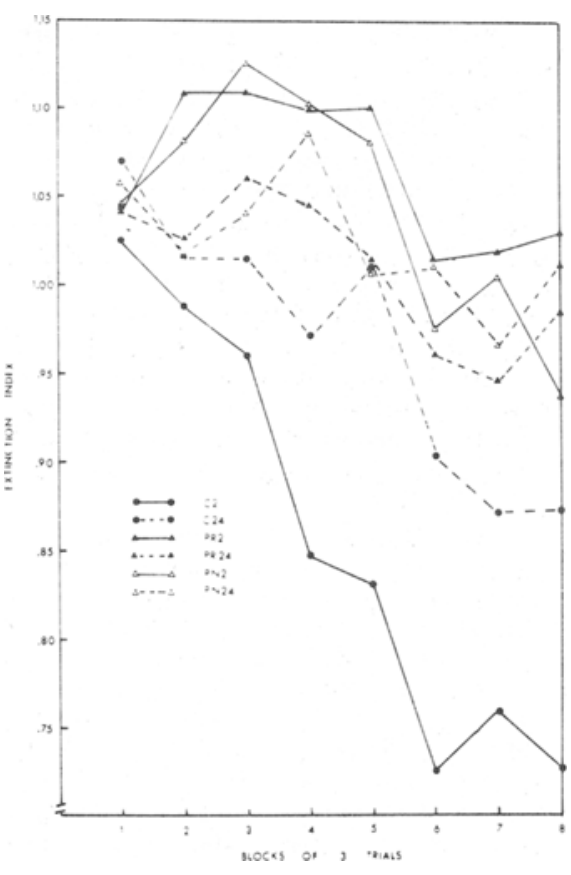

Fig. 1. Extinction index for all six acquisition conditions (see text).
The results as a whole do not seem to support Capaldi's aftereffects hypothesis. All partially reinforced Ss were significantly more resistent to extinction than consistently reinforced Ss. No attenuated PRE was evident for either Group PN2 or Group PN24, relative to their respective $\mathrm{PR}$ control groups. The present results support and extend those of Lobb \& Runcie (1967), in that no attenuated PRE was obtained when the ITR was administered following longer intervals ( 2 or $24 \mathrm{~h}$ ) than the $1-\mathrm{h}$ interval used by Lobb \& Runcie (1967). The fact that the PRE was not abolished in both the latter and present experiment, despite the administration of ITR, implies that perhaps the aftereffects of nonreward have a much shorter life span than that recently claimed by Capaldi (1967). This generalization becomes more plausible when one considers that similar results were obtained in each experiment, although both differed in many respects, e.g., the reinforcers, ITIs, and the place where the ITR was administered, etc., were quite different in each experiment. Apparently, then, with N-ITR intervals of $60 \mathrm{~min}$ or more, the intertrial reinforcement procedure is ineffective in attenuating the PRE. The validity of this statement is contingent upon the assumption that long $N(R)$-ITR intervals do not make it easier for $S$ to discriminate a regular trial from an ITR trial.

\section{REFE RENCES}

CAPALDI, E. J. A sequential hypothesis of instrumental learning. In $\mathrm{K}$. W. Spence and J. T. Spence (Eds.). The psychology of learning and motivation. New York: Academic Press. 1967.

CAPALDI, E. J.; \& MINKOFF, R. Change in the stimulus produced by nonreward as a function of time. Psychonomic Science, $1966,6,321-322$.

CAPALDI, E. J., \& OLIVIER, W. P. Effect of intertrial reinforcement following a substantial number of consistently rewarded trials. Joumal of Experimental Psychology, 1967, 75, 135-138.

CAP ALDI, E. J., \& SPIVEY, J. E. Intertrial reinforcements and aftereffects at 24-hour intervals. Psychonomic Science, 1964, 1, 181-182.

CAPALDI, E. J.. \& WILSON, N. B Intertrial reinforcement: A test of several hypotheses. Psychonomic Science, 1968. 13, 169-170.

LOBB, H., \& RUNCIE, D. Intertrial reinforcement as interference with consolidation. Psychonomic Science, $1967,9,25-26$.

McCAIN, G.. \& POWER, R. Extinction as a function of reinforcement conditions in the start box. Psychonomic Science, $1966,5,193-194$.

SHANAB, M. E., \& COTTON, J. W. Effects of runway training on behavior in the T-maze. Psychonomic Science, 1970, 19. 129-130. 